\title{
Quantitative ultrastructural studies of gall bladder epithelium in gall stone free subjects and patients with gall stones
}

\author{
S Sahlin, J Ahlberg, K Einarsson, R Henriksson, Å Danielsson
}

\begin{abstract}
The present study aimed at a further evaluation of the role of glycoproteins in the formation of cholesterol gall stones in man. An electron microscopic morphometric study of the gall bladder epithelium was performed in six gall stone free subjects and 12 gall stone patients. Six of the gall stone patients were treated with ursodeoxycholic acid three weeks before cholecystectomy. The number and the volume density of the mucin containing secretory granules, were not significantly increased in gall stone patients compared with gall stone free subjects. Treatment with ursodeoxycholic acid did not affect the number or volume density of the secretory granules. Thus, these results do not give evidence for that the degree of cholesterol saturation influences mucin content in the gall bladder wall of man. A major new finding was that gall stone patients had a markedly reduced total lysosome area and volume density of lysosomes compared with gall stone free subjects, a finding which may be related to a decreased intracellular degradation of protein and/or mucin.
\end{abstract}

Supersaturated bile is considered to be a necessary factor for cholesterol gall stone formation. As supersaturated bile is also a common finding in subjects without gall stones, however, other factors seem to be of importance..$^{1-3} \mathrm{~A}$ crucial event in gall stone formation seems to be the formation of cholesterol crystals - that is, the nucleation process. ${ }^{3}$ The nucleation time is thus much shorter in gall bladder bile of gall stone patients compared with normal subjects. ${ }^{4}$

Rapid nucleation has been suggested to result either from an excess of pronucleating factors and/or a deficiency of antinucleating factors. ${ }^{5-7}$ Several studies using the cholesterol fed prairie dog as an experimental model of cholesterol gall stone formation have implicated gall bladder mucin as an important nucleating agent. ${ }^{8-13}$ Also mice fed a lithogenic diet develop cholesterol gall stones along with an increase in mucin production. ${ }^{14-17}$

Human gall bladder mucin accelerates nucleation of cholesterol crystals in model bile. ${ }^{18}$ Gallinger et $a l^{19}$ found that mucin from both abnormal and control bile shortens nucleation time in a dose dependent manner. They did not find any quantitative or qualitative differences, however, in mucin of normal and abnormal bile. ${ }^{20}$ Recent studies indicate an important role of mucin in the formation of biliary sludge as the first step of gall stone formation. ${ }^{21} 22$
Wahlin et $a l^{23}$ have shown that the mouse gall bladder epithelium has a basal secretion of glycoproteins. Electron microscopic and cytochemical studies have established that these mucous substances are present in secretory granules. ${ }^{23}$ Mice fed a lithogenic diet displayed an increased synthesis of glycoproteins in the gall bladder epithelium and an enhanced secretion before gall stone formation. ${ }^{14}$ These findings have been confirmed by Lee and $\mathrm{Scott}^{16}$ and recently by MacPherson et $a l^{2425}$ in ground squirrels.

The aim of the present investigation was to further evaluate the role of gall bladder glycoproteins in the pathogenesis of gall stone formation in man. For this purpose an electron microscopic morphometric study on human gall bladder epithelium was carried out with special reference to secretory granules and lysosomes in patients with cholesterol gall stones and gall stone free subjects. Also gall stone patients treated with ursodeoxycholic acid (UDCA), a bile acid known to make bile unsaturated with cholesterol and to induce gall stone dissolution, were studied.

\section{Methods}

\section{PATIENTS}

Gall bladder bile and tissue samples were collected in 18 patients undergoing cholecystectomy. Twelve consecutive gall stone patients in whom preoperative cholecystography had shown gall stones in well functioning gall bladders were studied. Furthermore six consecutive gall stone free subjects with well functioning gall bladders without stones, but with polyps or adenomyomas of the gall bladder wall which justified operation, were included as controls in the investigation. All were non-obese $(<120 \%$ of relative weight) (Table I), and had normal liver function tests. Six patients from the gall stone group were treated with UDCA during three

TABLE I Clinical parameters of the gall stone-free subjects, the untreated gall stone patients, and those treated with ursodeoxycholic acid (UDCA). The data are expressed as mean (SEM)

\begin{tabular}{|c|c|c|c|c|}
\hline & $\begin{array}{l}\text { Sex } \\
(M: F)\end{array}$ & $\begin{array}{l}\text { Age } \\
\text { (yrs) }\end{array}$ & $\begin{array}{l}\text { Relative } \\
\text { body } \\
\text { weight* } \\
(\%)\end{array}$ & $\begin{array}{l}\text { Cholesterol } \\
\text { crystals } \\
\text { (Patients: } n)\end{array}$ \\
\hline $\begin{array}{l}\text { Gall stone free }(n=6) \\
\text { Gall stone }(n=6) \\
\text { UDCA }(n=6)\end{array}$ & $\begin{array}{l}1: 5 \\
3: 3 \\
0: 6\end{array}$ & $\begin{array}{l}51(8) \\
42(4) \\
49(6)\end{array}$ & $\begin{array}{r}100(6) \\
100(5) \\
96(6)\end{array}$ & $\begin{array}{l}1 \\
3 \\
2\end{array}$ \\
\hline
\end{tabular}

$\star$ Calculated as $\frac{\text { body weight }(\mathrm{kg})}{\text { length }(\mathrm{cm})-100} \times 100 \%$

\author{
Sahlin \\ K Einarsson \\ R Henriksson \\ Correspondence to: Dr Staffan \\ Sahlin, Department of \\ Surgery, Danderyd Hospital, \\ S-182 88 Danderyd, Sweden. \\ Accepted for
15 May 1989 \\ Danderyd Hospital and \\ Huddinge University \\ Institutet, Stockholm and \\ Histology and Medicine,
}


weeks before operation $(15 \mathrm{mg} / \mathrm{kg}$ body weight and day). All operations were performed between 9 and 12 am after an overnight fast.

Informed consent to participate was obtained from each patient, and the protocols were approved by the Ethical Committee at Karolinska Hospital (date 11/5/84).

\section{BILE COLLECTION AND POLARISATION MICROSCOPY}

The gall bladder was completely emptied of bile using sterile needle and syringe to avoid stratification of the bile. ${ }^{26} \mathrm{~A}$ regular cholecystectomy was then performed. Uncentrifuged gall bladder bile was kept in darkness at $37^{\circ} \mathrm{C}$ and examined with polarised light microscopy immediately after the operation and after three days. Cholesterol monohydrate crystals were identified by birefringence and typical flat rhomboidal shapes. The gall stones were classified as typical cholesterol stones by direct inspection and/or analysis in the laboratory. ${ }^{27} 28$

\section{TISSUE PREPARATION AND ELECTRON MICROSCOPY}

Immediately after the gall bladder had been removed, it was opened and inspected. A strip of the wall was excised. The mucosa was separated from the muscle layer and attached to a plate of cork and at once transferred to $1 \%$ osmiumtetraoxide in Millonig phosphate buffer $(0 \cdot 1 \mathrm{M}, \mathrm{pH}$ $7 \cdot 3,+4^{\circ} \mathrm{C}$ ) for two hours. Then, the preparation was rinsed and stored in $0.9 \% \mathrm{NaCl}$. The specimens were then dehydrated in graded ethanol solutions and propylene oxide and subsequently embedded in Epon 812. For electron cytochemical demonstration of mucin in the gall bladder epithelium, the periodic acid chromic acid silver stain (PA-CrA-silver) technique of Rambourg et al was used. ${ }^{29}$ These specimens were embedded in Vestopal. Sections were cut at a feeding rate of $70 \mathrm{~nm}$ on an LKB ultrotome (LBK Instruments Inc, Rockeville, Md, USA), and collected on naked copper grids or in the case of PA-CrA-Silver stain, on gold grids. After contrasting with uranyl acetate and lead citrate, the sections were examined in a Philips EM300 electron microscope.

\section{STEREOLOGICAL ANALYSIS}

Electron microscopic measurements were carried out on electron micrographs taken at random of principal cells that displayed the nucleus and part of the basal and apical surfaces of the section. Ten micrographs from each patient were randomly selected for stereological analyses. Profile areas and parameters of cells, nuclei and granules were estimated as well as granule number and size. The same parameters were also used for the lysosomes. All measurements were carried out on coded micrographs by one observer with MOP-Video plane (Kontron Bildanalyse, Munich, Germany). The morphometric analyses employed the standard measurement program Y2 and stereoprogram 5.42 (Kontron Bildanalyse). The volume densities of granules and lysosomes were calculated by divid- ing the respective area with the area of the cytoplasm (cell section minus nucleus section).

ANALYSIS OF BILIARY LIPIDS

For determination of cholesterol and phospholipids, a portion of the bile samples obtained was immediately extracted with 20 volumes of chloroform-methanol, 2:1 ( $\mathrm{vol} / \mathrm{vol})$. Cholesterol was determined by an enzymatic method ${ }^{30}$ and phospholipids by the method of Rouser et al. ${ }^{31}$ The total bile acid concentration in one aliquot of the bile samples was determined using the 3-alpha-hydroxy-steroid dehydrogenase assay. ${ }^{32}$ Cholesterol saturation was calculated as a percentage of the predicted cholesterol solubility at the respective biliary lipid concentration and composition, as described by Carey. ${ }^{33}$ The calculation of cholesterol saturation in patients treated with UDCA was performed without the correction factor suggested by Carey ${ }^{33}$ because this factor is valid only for a total lipid concentration of $10 \mathrm{~g} / \mathrm{dl}$.

STATISTICAL ANALYSIS

Significance of differences was evaluated with Student's $t$ test. Data are given as means (SEM).

\section{Results}

\section{LIGHT MICROSCOPY}

All gall bladders were routinely examined by a pathologist not involved in the study. Those with gall stones showed evidence of light to moderate chronic inflammation. In the gall stone free cases the suspected polyps were foldings of epithelium or cholesterolosis and the adenomyomas were confirmed. All gall stones were of cholesterol type.

\section{ELECTRON MICROSCOPY AND MORPHOMETRY}

The Figure illustrates the ultrastructure of gall bladder epithelial cells in gall stone free subjects and gall stone patients. The principal cells were almost the only cells found in the epithelium. The secretory granules are located in the apical part of the cell as demonstrated in conventional staining (Figs $a$ and $b$ ). The Rambourg technique (Figs $c$ and $d$ ) stains not only the mucin containing secretory granules, but also the lysosomes in a similar way, indicating chemically related contents. The lysosomes are larger and their content is more heterogeneous than the granules, which are abundant in the apical part of the cell. The lysosomes are also more lobated, compared with the granules, a finding which is in accordance with the work of Koga. ${ }^{3+}$

The results of the quantitative electron microscopic analysis with respect to mucin containing secretory granules are presented in Table II. The mean volume density and the number of secretory granules tended to be somewhat higher in the gall stone group as well as in the UDCA group compared with the gall stone free group, but the differences did not reach statistical significance. 

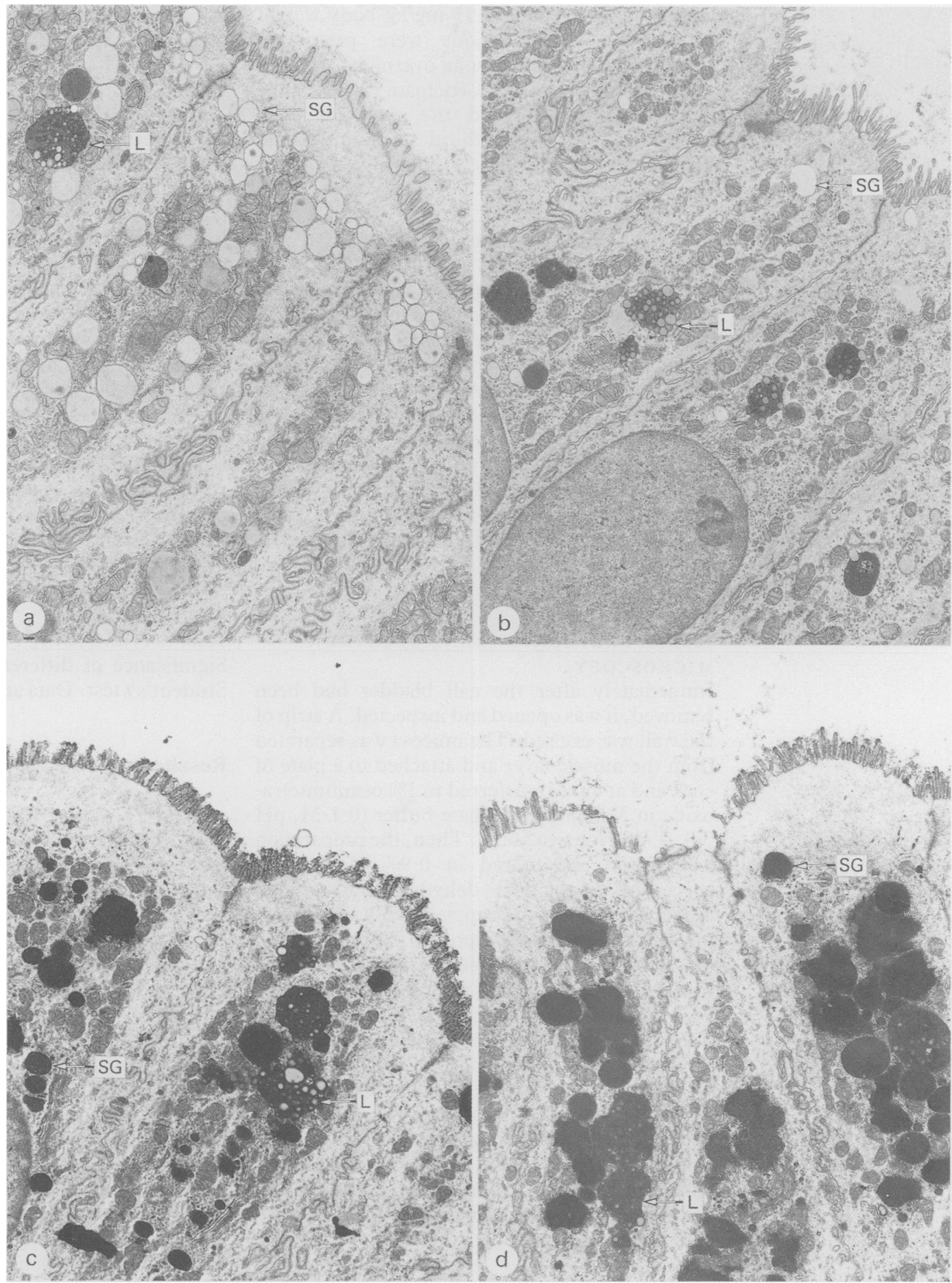

Figure: Micrographs of gall bladder principal cells from patients without (GSF) and with gall stone disease (GS). The upper panel shows electron micrographs of $(a) G S F$ and $(b) G S$ in conventional staining. The lower panel shows electron micrographs after PA-CrA-silver stain ${ }^{29}$ for $G S F(c)$ and $G S(d)$. Arrows point at lysosomes $(L)$ and secretory granules $(S G)$.

Table II displays that the lysosome area as well as the volume density of lysosomes in the gall stone free group were three to four times higher compared with both gall stone and UDCA groups. The volume density was calculated as lysosome area/(cell area-nucleus area). The number of lysosomes was about the same in the different groups.

LIPID ANALYSIS OF BILE

The concentration of total lipids in the gall stone free group was higher compared with the gall stones as well as the UDCA group (Table III).
The cholesterol saturation in the gall stone group was increased compared with the gall stone free group. UDCA treatment normalised the cholesterol saturation.

CHOLESTEROL CRYSTALS

Three patients in the gall stone and one in the gall stone free group had monohydrate crystals in the gall bladder bile (Table I). Two in the UDCA group had crystals, both with unsaturated bile. The crystals all appeared at the first day. The bile samples were inspected for at least three more days. 
TABLE II Secretory granules and lysosomes in gall bladder epithelium of gall stone free subjects, untreated gall stone patients, and gall stone patients treated with ursodeoxycholic acid (UDCA). The values are expressed as mean (SEM)

\begin{tabular}{|c|c|c|c|}
\hline & $\begin{array}{l}\text { Gall stone } \\
\text { free }(n=6)\end{array}$ & $\begin{array}{l}\text { Gall stone } \\
(n=6)\end{array}$ & $\begin{array}{l}\text { UDCA } \\
(n=6)\end{array}$ \\
\hline \multicolumn{4}{|l|}{ Granules } \\
\hline Volume density (\%) & $3 \cdot 2(1 \cdot 0)$ & $4 \cdot 1(1 \cdot 1)$ & $4 \cdot 8(1 \cdot 7)$ \\
\hline Total granule area $\left(\mu \mathrm{m}^{2}\right)$ & $5 \cdot 1(2 \cdot 0)$ & $5 \cdot 5(1 \cdot 7)$ & $7 \cdot 6(3 \cdot 0)$ \\
\hline $\begin{array}{l}\text { Number of granules per } \\
\text { cell }(n)\end{array}$ & $12 \cdot 7(2 \cdot 2)$ & $17 \cdot 4(4 \cdot 2)$ & $22 \cdot 3(7 \cdot 2)$ \\
\hline Mean granule area $\left(\mu \mathrm{m}^{2}\right)$ & $0 \cdot 3(0 \cdot 1)$ & $0 \cdot 3(0 \cdot 1)$ & $0.3(0.0)$ \\
\hline \multicolumn{4}{|l|}{ Lysosomes } \\
\hline Volume density (\%) & $3 \cdot 8(0 \cdot 4)$ & $1 \cdot 1(0 \cdot 2) \ddagger$ & $1 \cdot 0(0 \cdot 4)$ \\
\hline Total lysosome area $\left(\mu \mathrm{m}^{2}\right)$ & $5 \cdot 4(0.6)$ & $1 \cdot 5(0 \cdot 4) \ddagger$ & $1 \cdot 5(0 \cdot 7)$ \\
\hline Number of lysosomes (n) & $5 \cdot 5(1 \cdot 7)$ & $3 \cdot 7(1 \cdot 1)$ & $3.9(1.4)$ \\
\hline Mean lysosome area $\left(\mu \mathrm{m}^{2}\right)$ & $1.5(0.4)$ & $0.5(0 \cdot 1)^{\star}$ & $0.4(0.0)$ \\
\hline
\end{tabular}

TABLE III Lipid composition and cholesterol saturation in gall bladder bile of gall stone free subjects, untreated gall stone patients, and gall stone patients treated with ursodeoxycholic acid (UDCA). The values are expressed as mean ( $S E M)$

\begin{tabular}{lccc}
\hline & $\begin{array}{c}\text { Gall stone } \\
\text { free }(n=6)\end{array}$ & $\begin{array}{l}\text { Gall stone } \\
(n=6)\end{array}$ & $\begin{array}{l}\text { UDCA } \\
(n=6)\end{array}$ \\
\hline Cholesterol (mol\%) & $\begin{array}{c}5 \cdot 7(0 \cdot 8) \\
\text { Bile acids (mol\%) }\end{array}$ & $\begin{array}{c}7 \cdot 8(0 \cdot 8(10 \cdot 9) \\
65 \cdot 8(1 \cdot 6)\end{array}$ & $\begin{array}{c}3 \cdot 7(0 \cdot 7) \\
77 \cdot 0(4 \cdot 5)\end{array}$ \\
Phospholipids (mol\%) & $25 \cdot 5(1 \cdot 8)$ & $26 \cdot 5(1 \cdot 5)$ & $19 \cdot 4(3 \cdot 8)$ \\
Lipid concentration (g/dl) & $15 \cdot 0(1 \cdot 5)$ & $7 \cdot 9(1 \cdot 7)^{\star}$ & $4 \cdot 8(0 \cdot 8) \dagger$ \\
Cholesterol saturation (\%) & $69(7)$ & $102(9)^{\star}$ & $64(9)$ \\
\hline
\end{tabular}

$\star$ Significantly different from gall stone free subjects $\mathrm{p}<0.05$; tp $<0.001$.

\section{Discussion}

A number of studies in recent years indicate that the gall bladder secretes or releases one or several factors which may accelerate the nucleation process in cholesterol gall stone formation. ' This factor may be a nucleating agent in itself or may act by neutralising an antinucleating agent normally present in bile. In either case the result is an accelerated nucleation in supersaturated bile. Several animal investigations suggest mucin to be a pronucleating factor or cofactor." Electron microscopic studies of mouse gall bladder epithelium have shown that the secretory granule volume, containing glycoproteins, increases when the animals are fed with a lithogenic diet. ${ }^{1416}$ This process precedes the crystal and gall stone formation. Similar results have been obtained in the gall bladder of ground squirrels. ${ }^{25}$

In the present study a tendency of increased secretory granule volume was found in gall stone patients compared with gall stone free patients. No statistical significance could be established, however, with respect to this parameter. Nor did the UDCA treated patients with unsaturated bile show a significant change in volume density of secretory granule. The latter finding may implicate that the degree of cholesterol saturation is of no major importance for the quantity of intracellular mucin secretory granules in man.

Thus, our results do not give evidence that gall stone patients have an increased content of glycoproteins in the principal cells of the gall bladder or that the cholesterol saturation would influence this. It should be pointed out, however, that our data only apply to the fasting state of the gall bladder. Studies in the mouse have shown that after fasting there is a low content of mucin granules in the gall bladder epithelium which increases on refeeding. ${ }^{15}$ Furthermore our data do not exclude the possibility that gall stone patients may have an increased mucin secretion and content in the gall bladder bile. Previously, Bouchier $e t a l^{35}$ found an increased concentration of hexosamine, a marker for mucin, in gall bladder bile of gall stone patients. Similar results were reported by Mingrone $e t a l^{36}$ and have also been obtained in our laboratory. ${ }^{37}$ Also Lee et $a l^{38}$ found raised glycoprotein concentration in gall bladder bile of gall stone patients. In contrast, Harvey et $a l^{20}$ reported that the mucin glycoprotein concentration of gall bladder bile in gall stone patients and gall stone free subjects were not significantly different. Some of their gall stone patients, however, did have raised concentrations of mucin glycoprotein.

Do glycoproteins play a role in the formation of cholesterol gall stones? Levy $e t a l^{18}$ as well as Gallinger $e t a l^{19}$ have shown that human gall bladder mucin accelerates the nucleation of cholesterol crystals. On the other hand, Harvey et $a l^{20}$ could not find any correlation between human gall bladder mucin concentration and cholesterol nucleation time. Neither did Whiting and Watts ${ }^{39}$ find any correlation between the concentration of biliary hexosamine and cholesterol crystal formation in man. The mechanism by which mucin promotes nucleation is not known. Several authors have observed that cholesterol monohydrate crystal formation occurs in a mucus layer adherent to the gall bladder epithelium. Thus, the mucus layer might provide a favourable environment for the nucleation process. Smith ${ }^{+0}$ recently reported on the capacity of mucin to bind cholesterol and phospholipids in a model bile. Binding of phosphatidyl-choline and cholesterol to human gall bladder mucin increased as a function of cholesterol saturation. In supersaturated bile the binding of especially cholesterol to mucin was markedly increased. It is thus possible that mucin may act as a pronucleating agent in the formation of cholesterol crystals in supersaturated bile mainly because of its hydrophobic binding of cholesterol.

A major new finding was that the volume density of lysosomes was three to four times higher in the gall stone free group compared with the gall stone and UDCA groups. The lysosome is a cell organelle that originates from the vesicles of the Golgi complex or from the endoplasmatic reticulum or from both. The lysosomes contain a great number of hydrolytic enzymes, particularly acid phosphatase, and enzymes and products of digested polysaccharides and proteins..$^{4142}$ The lysosome content stained similarly to the mucin granules, which may suggest a common origin, such as an intracellular degradation of mucin granules. In other epithelial tissues, it has been suggested that the lysosomal system digests secretory granules during periods of reduced secretory stimulation. ${ }^{43}$ Kouroumalis $e t \mathrm{al}^{445}$ found a close correlation between neutral and acid esterases and with acid phosphatase indicating a lysosomal location. The distribution of the latter enzyme activity corresponded to a lysosomal location. Gall stone free patients displayed high concentrations of mucosal esterase, acid phosphatase 
and beta-glucuronidase activities whereas low concentrations were found in patients with cholesterol gall stones. ${ }^{45}$

Gallinger $e t a l^{+6}$ recently reported that gall stone patients have a higher concentration of total protein in the gall bladder bile compared with gall stone free subjects. The protein concentration correlated with the nucleation time in the gall stone group. The hepatic bile protein concentrations, however, were similar in the two groups of patients. The results suggested that the gall stone patients may have a decreased capacity to absorb or degrade protein in the gall bladder. The finding of a reduced lysosome content may explain a decreased protein degradation in the gall bladder wall. In a smaller series of patients, however, Yamazaki et $a l^{47}$ did not find any significant difference in the concentration of total protein in gall bladder bile between gal stone free subjects and gall stone patients. An alternative explanation could be that the lysosomes are normally involved in intracellular degradation of mucin granules. A reduced content of these organelles may thus reflect a defect in elimination of mucin granules, which otherwise are released into the gall bladder lumen and may act as a nidus for cholesterol crystal formation. Kouroumalis et $a l^{45}$ presented a third explanation that lysosomal enzymes are released together with mucin granules into the gall bladder lumen, where they hydrolyse conjugated bilirubin into unconjugated. The unconjugated bilirubin can easily precipitate as calcium bilirubinate, forming nidus for gall stones.

In conclusion, the present study did not show any statistically significant increase in secretory granules in the gall bladder epithelial cell in gall stone patients after an overnight fast. This does not, however, exclude the possibility of increased mucin secretion as quantitative morphology gives a static picture of a dynamic process including granule synthesis, intracellular degradation and secretion of mucin granule. It should also be mentioned that the studies were conducted on patients who had already had gall stones for several years, and thus do not exclude an increase of secretory granules in the very early stage of gall stone formation. The finding of diminished cellular lysosome content may limit the intracellular mucin degradation. Further studies are needed to evaluate the importance of the lysosomes in the pathogenesis of cholesterol gall stone formation.

The skilful technical assistance of Ms Ann-Christine Andersson, Ms Lisbet Benthin, Ms Berith Lundström and Ms Ingel Svensson is gratefully acknowledged. The investigation was supported by grants from the Swedish Medical Research Council (Nos 4992 and 4793 ).

1 Ahlberg J, Angelin B, Einarsson K. Hepatic 3-hydroxy-3 methylglutaryl coenzyme A reductase activity and biliary lipid composition in man: Relation to cholesterol gallstone disease and effects of cholic acid and chenodeoxycholic acid treatment. F Lipid Res 1981; 22: 410-22.

2 Holzbach TR, Marsh M, Olszewski M, Holan K. Cholestero solubility in bile: Evidence that supersaturated bile is frequent in healthy man. 7 Clin Invest 1973; 52: 1467-79.

3 Smith BF, LaMont JT. The pathogenesis of gallstones. Hosp ract 1984; 19: 93-104.

4 Holan KR, Holzbach RT, Hermann RE, Cooperman AM Claffey WJ. Nucleation time: a key factor in the pathogenesis of cholesterol gallstone disease. Gastroenterology 1979; 77: 611-7.

5 Burnstein MJ, Ilson RG, Petrunka CN, Taylor RD, Strasberg SM. Evidence for a potent nucleation factor in the gallbladder bile of patients with cholesterol gallstones. Gastroenterology 1983; 85: 801-7.
6 Holzbach RT, Kibe A, Thiel E, Howell JH, Marsh M, Hermann RE. Biliary proteins: Unique inhibitors of cholesterol crystal nucleation in human gallbladder bile. 7 Clin Invest 1984; 73: 34-45.

7 Holzbach RT. Recent progress in understanding cholestero crystal nucleation as a precursor to human gallstone formation. Hepatology 1986; 6: 1403-6.

8 Lee SP, LaMont JT, Carey MC. Role of gallbladder mucus hypersecretion in the evaluation of cholesterol gallstones. f Clin Invest 1981; 67: 1712-23.

9 Doty JE, Pitt HA, Kuchenbecker SL, Porter-Fink V, DenBesten LW. Role of gallbladder mucus in the pathogenesis of cholesterol gallstones. Am F Surg 1983; 145: 54 61 .

10 Zak RA, Frenkiel PG, Marks JW, Bonorris GG, Allen A Schoenfield LJ. Cyclic nucleotides and glycoproteins during formation of cholesterol gallstones in prairie dogs Gastroenterology 1984; 87: 263-9.

11 LaMont JT, Smith BF, Moore JRL. Role of gallbladder mucin in pathophysiology of gallstones. Hepatology 1984; 4: 51-6.

12 La Morte WW, Booker ML, Scott TE, Williams LFW Jr. Increases in gallbladder prostaglandin synthesis before the formation of cholesterol gallstones. Surgery 1985; 98: 445-51.

$13 \mathrm{Li} \mathrm{YF}$, Moody FG, Weisbrodt NW, et al. Gallbladder contractility and mucus secretion after cholesterol feeding in the prairie dog. Surgery 1986; 100: $900-4$.

14 Wahlin $T$. Effects of lithogenic diet on mouse gallbladder epithelium. Virchows Arch 1976; 22: 273-86.

15 Wahlin T. Synthesis of glycoprotein in the Golgi complex of the mouse gallbladder epithelium during fasting, refeeding and gallstone formation. Histochemistry 1976; 5: 133-40.

16 Lee SP, Scott AJ. The evolution of morphologic changes in the gallbladder before stone formation in mice fed a cholesterolcholic acid diet. Am F Pathol 1982; 108: 1-8.

17 Whiting MJ, Watts JMck. Gall-bladder glycoprotein synthesis and secretion during cholesterol gallstone formation in the mouse. F Gastroenterol Hepatol 1986; 1: 323-32.

18 Levy PF, Smith BF, LaMont JT. Human gallbladder mucin accelerates in vitro nucleation of cholesterol in artificial bile. Gastroenterology 1984; 87: 270-5.

19 Gallinger S, Taylor RD, Harvey PRC, Petrunka CN Strasberg SM. Effect of mucus glycoprotein on nucleation time of human bile. Gastroenterology 1985; 89: 648-58.

20 Harvey PRC, Rupar CA, Gallinger S, Petrunka CN, Strasberg SM. Quantitative and qualitative comparison of gall bladder mucus glycoprotein from patients with and without gal stones. Gut 1986; 27 : 374-81.

21 Lee SP, Nichols JF. Nature and composition of biliary sludge. Gastroenterology 1986; 90: 677-86.

22 Malet PF, Williamson CE, Trotman BW, Soloway RD. Composition of pigmented centers of cholesterol gallstones. Hepatology 1986; 6: 477-81

23 Wahlin T, Bloom GD, Carlsöö B, Rhodin L. Effects of fasting and refeeding on secretory granules of mouse gallbladder epithelium. A quantitative electron microscopic study. epithelium. A quantitative electr
Gastroenterology 1976; 70: 353-8.

24 MacPherson BR, Pemsingh RS, Scott GW. Experimental cholelithiasis in the ground squirrel. Lab Invest 1987; 56 : $138-45$.

25 Pemsingh RS, MacPherson BR, Scott GW. Mucus hypersecretion in the gallbladder epithelium of ground squirrels ed a lithogenic diet for the induction of cholesterol gallstones. Hepatology 1987; 7: 1267-71.

$26 \mathrm{Tera} \mathrm{H}$. Stratification of human gallbladder bile in vivo. Acta Chir Scand 1960; 256 (suppl): 4-65.

27 Trotman BW, Ostrow JD, Soloway RD. Pigment vs cholesterol cholelithiasis: comparison of stone and bile composition. Am F Dig Dis 1974; 19: 585-90.

28 Whiting MJ, Down RH, Watts JMcK. Biliary crystals and granules, the cholesterol saturation index, and the predicgranules, the cholesterol saturation index, and the predi
tion of gallstone type. Surg Gastroenterol 1982; 1: 17-21.

29 Rambourg A, Hernandes V, Leblond CP. Detection of complex carbohydrates in the Golgi apparatus of rat cells fCell Biol 1969; 40: 395-414.

30 Roda A, Festa D, Sama C, et al. Enzymatic determination of cholesterol in bile. Clin Chim Acta 1975; 64: 337-41.

31 Rouser G, Sidney F, Akira Y. Two dimensional thin-layer chromatography separation of polar lipids and determination of phospholipids by phosphorous analysis of spots. Lipids 1975; 5: 494-6.

32 Fausa $\mathrm{O}$, Skålhegg $\mathrm{BA}$. Quantitative determination of bile acids and their conjugates using thin-layer chromatography and purified 3-alpha-hydroxy-steroid dehydrogenase. Scand and purified 3-alpha-hydroxy-s

33 Carey CM. Critical tables for calculating the cholesterol saturation of native bile. $\mathcal{F}$ Lipid Res 1978; 19: 945-55.

$34 \mathrm{Koga}$ A. Electron microscopic observations on the mucous secretory activity on the human gallbladder epithelium Z Zellforsch 1973; 139: 463-71

35 Bouchier IAD, Cooperband SR, El Kodsi BM. Mucous substances and viscosity of normal and pathological human bile. Gastroenterology 1965; 49: 343-53.

36 Mingrone G, Greco AV, Finotti E, Passi S. Free fatty acids: a stimulus for mucin hypersecretion in cholesterol gallstone biles. Biochim Biophys Acta 1988; 958: 52-9.

37 Sahlin S, Danielsson A, Angelin B, Reihnér E, Henriksson R, Einarsson K. Mucin in gall bladder bile of gall stone patients: influence of treatment with chenodeoxycholic acid and ursodeoxycholic acid. Gut 1988; 29: 1506-10.

38 Lee SP, Lim TH, Scott AJ. Carbohydrate moieties of glycoproteins in human hepatic and gall bladder bile, gall bladder

39 Whiting MJ, Watts JMck. Supersaturated bile from obese patients without gallstones supports cholesterol crystal patients without gallstones supports cholesterol crystal
growth but not nucleation. Gastroenterology 1984; 86: 243-8. 
40 Smith BF. Human gall bladder mucin binds biliary lipids and promotes cholesterol crystal nucleation in model bile. $\mathcal{F}$ Lipid Res 1987; 28: 1088-97.

41 DeDuve C, Wattiaux R. Functions of lysosomes. Ann Rev Physiol 1966; 28: 435-92.

42 Novikoff A, Holtzman E. Cells and organelles. New York: Holt Reinhart and Winston, 1970.

43 Hand R. The effects of acute starvation on parotide acinar cells. Ultrastructural and cytochemical observation on ad libitum-fed and starved rats. Am $\mathcal{F}$ Anat $1972 ; 135: 71-92$.

44 Kouroumalis E, Hopwod D, Ross PE, Bouchier IAD. Human gallbladder epithelium: non-specific esterases in cholecystitis. F Pathol 1984; 142: 151-9.

45 Kouroumalis E, Hopwood D, Ross PE, Milne G, Bouchie IAD. Gallbladder epithelial acid hydrolases in human cholecystitis. F Pathol 1983; 139: 179-91.

46 Gallinger S, Harvey PRC, Petrunka CN, Ilson RG, Strasberg SM. Biliary proteins and the nucleation defect in cholesterol cholelithiasis. Gastroenterology 1987; 92: 867-75.

47 Yamazaki K, Powers SP, LaRusso NF. Biliary proteins: Assessment of quantitative differences between subjects
with and without gallstones. $\mathcal{F}$ Lipid Res 1988; 29: 1055-63. 